\title{
A comparison of measured HONO uptake and release with calculated source strengths in a heterogeneous forest environment
}

M. Sörgel et al.

Correspondence to: M. Sörgel (m.soergel@mpic.de)

The copyright of individual parts of the supplement might differ from the CC-BY 3.0 licence. 


\section{$1 \quad 1$ Site description}

3 A detailed description of the research area and measurement sites can be found in Gerstberger

4 et al. (2004), Staudt and Foken (2007) and Foken et al. (2012). A detailed description of the

5 clearing site and the intensive campaign EGER IOP-3 can be found in Serafimovich et al.

6 (2011). Figure S1 shows the heterogeneity of the area and the three measurements sites.

7

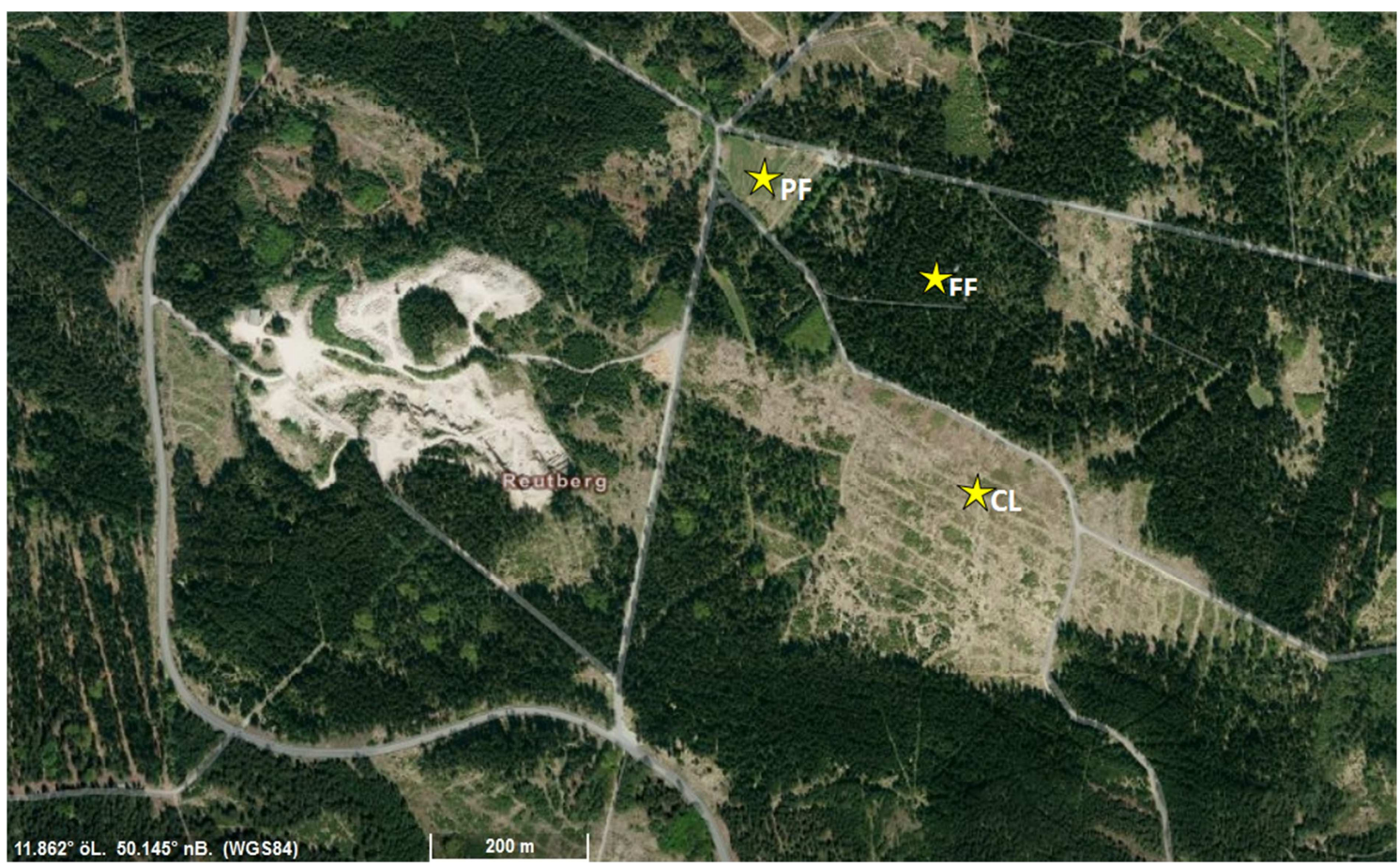

9 Figure S1: Aerial view (data source: Bayerische Vermessungsverwaltung - www.geodaten.bayern.de) of the 10 measurement sites shows the heterogeneous forest landscape of the research area with the marked sites forest 11 floor (FF), clearing (CL) and "Pflanzgarten" (PF). The white area on the left side of the picture is a stone pit. 12 Most roads are forest roads except the curvy road running from the middle of the bottom of the picture to the 13 upper left corner (i.e. from the south to the north-west of the measurement sites). This road is a country road with 14 about 2100 cars per working day (Foken et al., 2012). The clearing has the dimensions of $\sim 300 \mathrm{x} 400 \mathrm{~m}$.

\section{Lift system}

18 Figure S2 shows the lift system used for sampling at different heights. The system consists of 19 a vertical linear guide system (Igus, Cologne, Germany) and a stepper motor with a custom 20 built control unit (electronics workshop, University of Bayreuth). The heights are 21 programmable and ranged between $0.1 \mathrm{~m}$ above ground level to $1.6 \mathrm{~m}$ above ground level. 


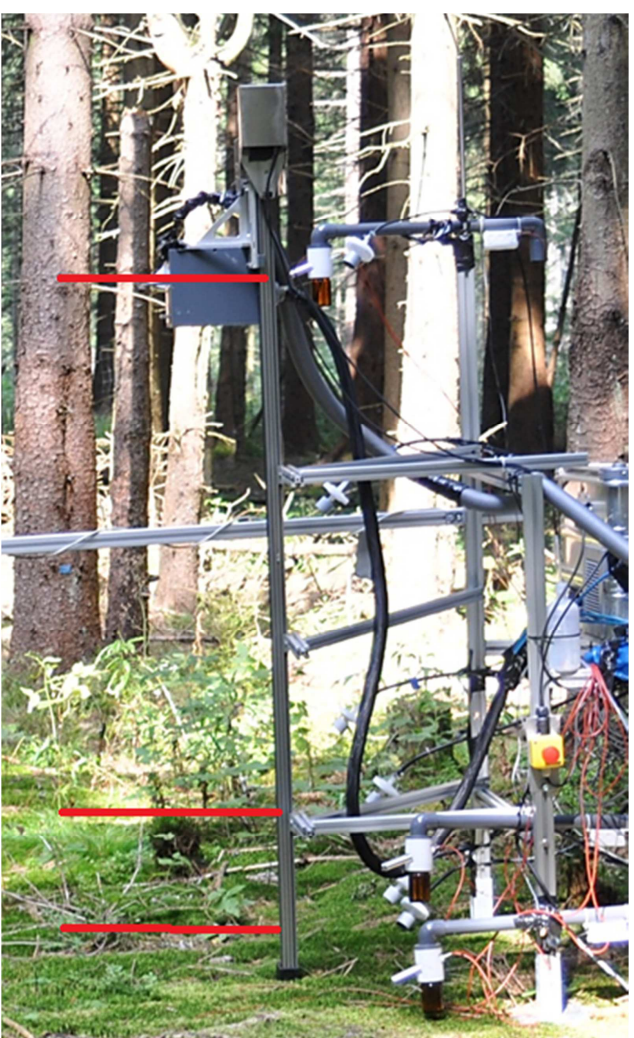

2 Figure S2: External sampling unit of the LOPAP (grey box) and inlet for $\mathrm{NO}_{\mathrm{x}}$ installed on the lift system at the 3 forest floor. Three positions $(1.6 \mathrm{~m}, 0.4 \mathrm{~m}$ and $0.1 \mathrm{~m})$ used for the profile measurements are indicated in red.

\section{Measured trace gas profiles (all heights)}

6

7 The following figures (Figure S3 to S5) show the trace gas profiles of $\mathrm{NO}, \mathrm{NO}_{2}$ and $\mathrm{HONO}$

8 that were measured consecutively by the above described lift system. The first period $\left(27^{\text {th }}\right.$ of

9 June to $30^{\text {th }}$ of June 2011) of the 2011 campaign is shown in Fig. S3, the second part (11 ${ }^{\text {th }}$ of 10 July to $13^{\text {th }}$ of July) in Fig. S4. In between the instrument was broken. Measurements were 11 made in a clearing (see Fig. S1). Figure S5 shows the measurements at the forest floor (see 12 Fig. S2) during the 2012 campaign ( $3^{\text {rd }}$ of September to $9^{\text {th }}$ of September 2012). 

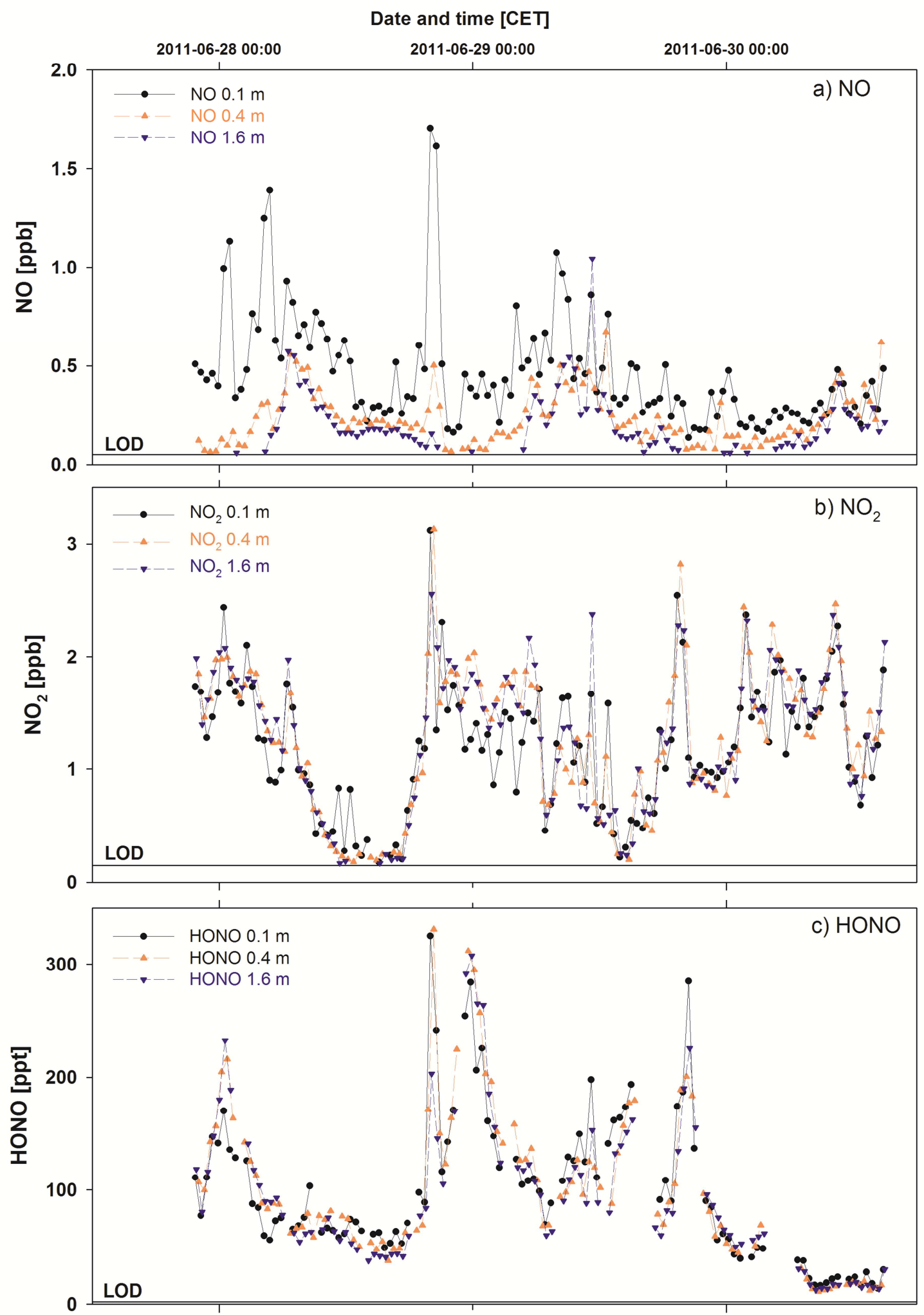

Figure S3: Trace gas profiles measured during the first period of the 2011 campaign in the clearing. The profiles were measured consecutively with a lift system. Heights are $0.1 \mathrm{~m}, 0.4 \mathrm{~m}$ and $1.6 \mathrm{~m}$ above ground. Panel a) NO, panel b) $\mathrm{NO}_{2}$ and panel c) $\mathrm{HONO}$ 

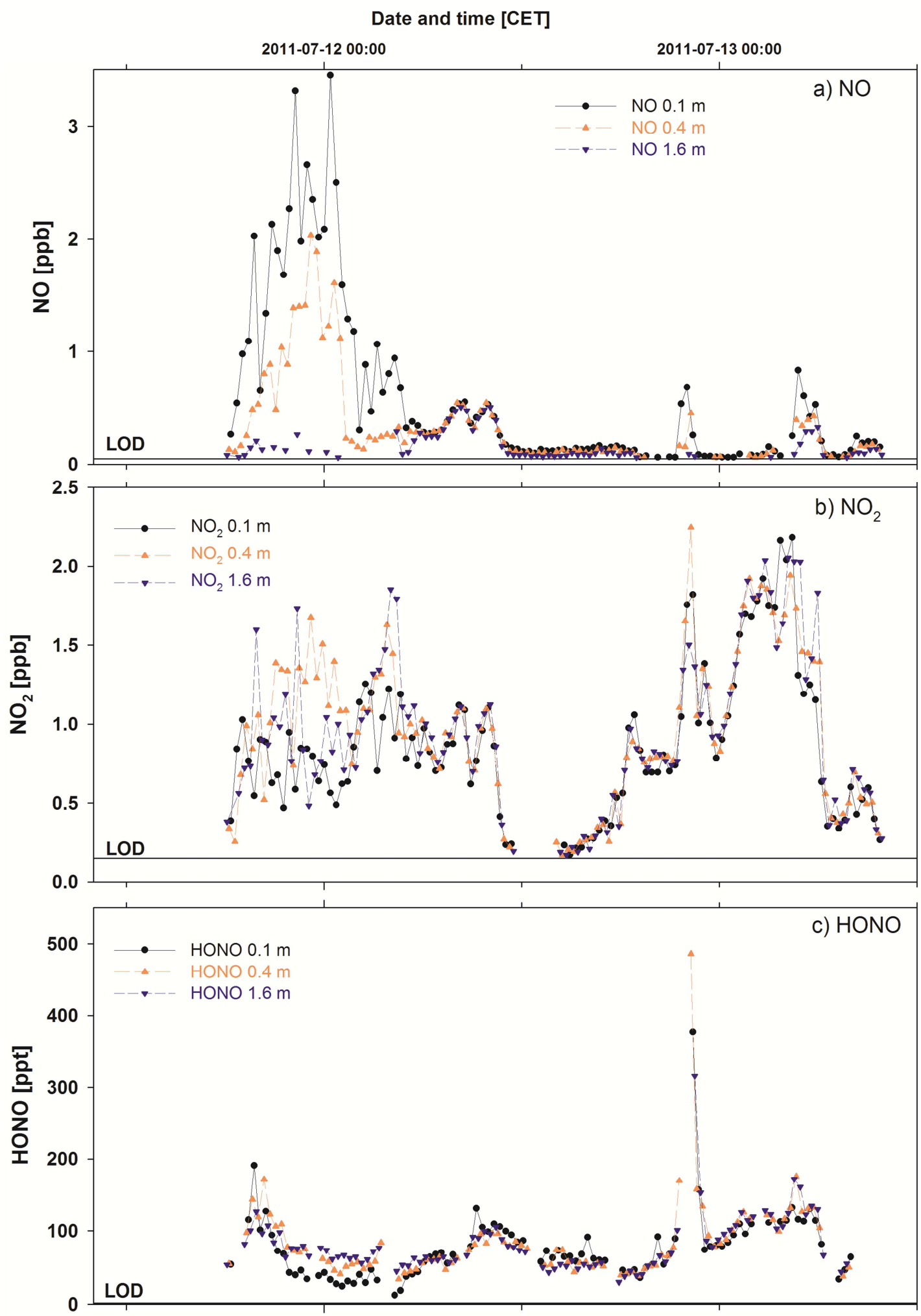

2 Figure S4: Trace gas profiles measured during the second period of the 2011 campaign in the clearing. The 3 profiles were measured consecutively with a lift system. Heights are $0.1 \mathrm{~m}, 0.4 \mathrm{~m}$ and $1.6 \mathrm{~m}$ above ground. Panel 4 a) $\mathrm{NO}$, panel b) $\mathrm{NO}_{2}$ and panel c) HONO. 

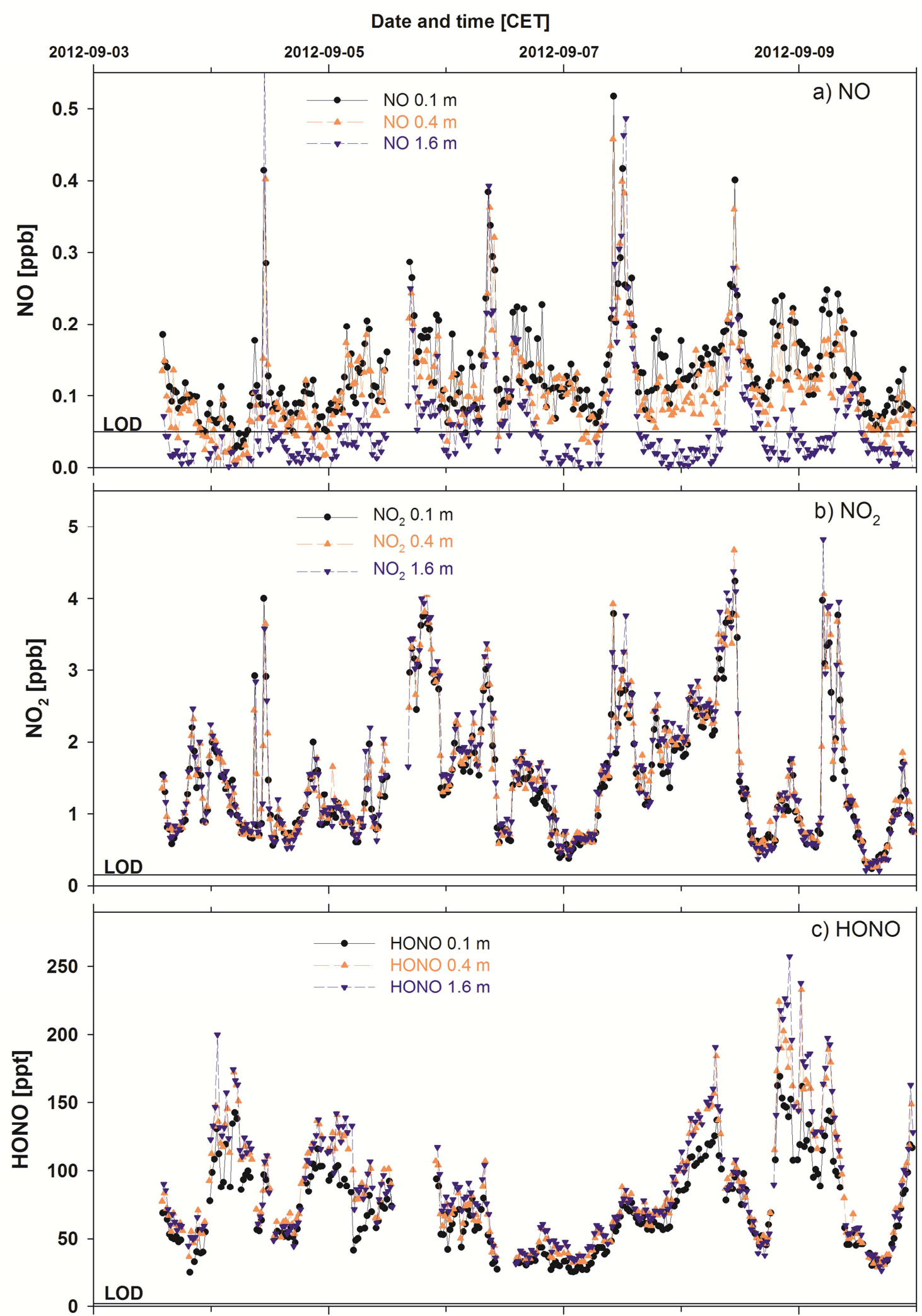

Figure S5: Trace gas profiles measured during the 2012 campaign at the forest floor. The profiles were measured consecutively with a lift system. Heights are $0.1 \mathrm{~m}, 0.4 \mathrm{~m}$ and $1.6 \mathrm{~m}$ above ground. Panel a) NO, panel b) $\mathrm{NO}_{2}$ and panel c) HONO. 


\section{Laboratory measurements of soil fluxes}

3 In order to evaluate potential soil HONO emissions, several soil samples were taken from the 4 sites where the lift system was located. The soil type is classified as haplic podzol over 5 granite bedrock (Gerstberger et al., 2004) for this area, but only the soil organic layer (O 6 horizon) was sampled. This organic layer is characterized by a high water holding capacity 7 and very low pH values (Gerstberger et al., 2004). On 30 Aug 2012, the first soil sample 8 (Sample 1) was taken from a hemicycle with a radius of about $10 \mathrm{~m}$ around the lift system. 9 The green moss on top of the soil $(0.8-1.5 \mathrm{~cm})$ was removed, and the Oe and Oa horizons were sampled separately in three replicates. These samples were transported on ice in a cooling box to the laboratory. The Oe soil sample was measured immediately after sampling, and the Oa soil sample was stored in a refrigerator for $24 \mathrm{~h}$ at $4{ }^{\circ} \mathrm{C}$ before measurement. For

13 samples 2-4, which were taken on 11 June 2013, the vegetation cover was removed and the 14 upper $5 \mathrm{~cm}$ of the $\mathrm{O}$ horizon was sampled by sampling rings. Three sampling rings have been 15 taken for one subsample. These samples were transported in a cooling box for about $10 \mathrm{~h}$ and 16 then stored at $4{ }^{\circ} \mathrm{C}$ in a refrigerator prior to analysis within the following 3 to 5 days. For each 17 site (forest/clearing) we chose two different types of understory vegetation for sampling. In the forest, the soil was covered by moss (Sample 1). As a prior study found higher NO emissions for blueberry than for moss in that respective forest patch (Bargsten et al. 2010), we also sampled a stand of blueberries nearby (Sample 2). At the clearing, the understory close to the lift system consisted mainly of grass and some small blueberry plants (Sample 4). We also took soil samples from the surrounding, which was dominated by blueberries on moist soil (Sample 3). 

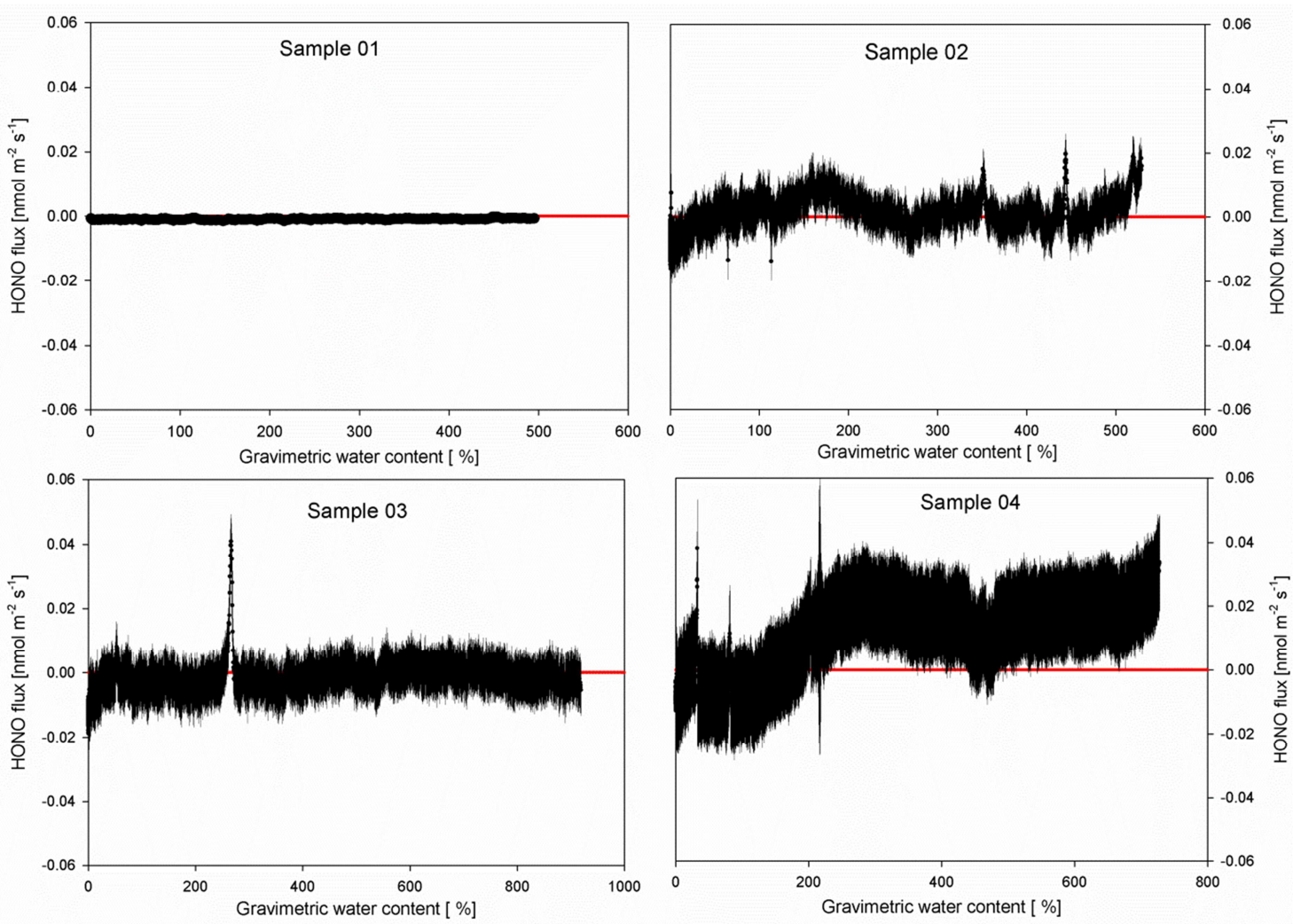

Figure S6: HONO fluxes from four different soil samples measured in a dynamic laboratory chamber according to Oswald et al. (2013). Sample 1 was taken from the forest floor covered with moss, whereas for sample 2 the ground was covered by blueberries. Samples 3 and 4 were taken on the clearing from moist soil covered by blueberries and from ground covered by grass, respectively. The differences in the errors are due to different detection limits $(0.5 \mathrm{ppt}$ to $6 \mathrm{ppt})$ for the LOPAP instrument.

For each understory type, three subsamples were taken. These have been combined into one sample which was measured in the laboratory system. The laboratory setup to measure the emission fluxes was described in detail elsewhere (Oswald et al., 2013, Wu et al., 2014). Briefly, the soil samples were passed through $16 \mathrm{~mm}$ sieves (instead of $2 \mathrm{~mm}$ ), reducing the influence of the destruction of the structure of soil organic matter on trace gas emission (Bargsten et al., 2010). Roots were removed to the extent possible, $50 \mathrm{~g}$ of soil were put in a petri dish $\left(\mathrm{OD}=88 \mathrm{~mm}\right.$ ), and purified water (resistivity $18.2 \mathrm{M} \Omega \mathrm{cm}^{-1}$ ) was added to reach water holding capacity. The dish was placed in a Teflon chamber $(47 \mathrm{~L})$ within a climate cabinet at $15{ }^{\circ} \mathrm{C}$ for Sample 1 and $25^{\circ} \mathrm{C}$ for samples 2-4. The chamber was flushed with $8 \mathrm{~L}$ $\min ^{-1}$ of dry purified air, and the trace gas mixing ratios (NO, $\mathrm{NO}_{2}, \mathrm{O}_{3}, \mathrm{CO}_{2}, \mathrm{H}_{2} \mathrm{O}$ and HONO) were monitored in the chamber outflow. $\mathrm{NO}_{\mathrm{x}}$ was measured by chemiluminescence (Model 42i-TL Thermo Scientific, Franklin, MA, USA), ozone by UV-absorption (Model 49iThermo Scientific, Franklin, MA, USA), $\mathrm{CO}_{2}$ and $\mathrm{H}_{2} \mathrm{O}$ by infrared absorption (Model 840A, LI-COR,

21 Lincoln, Nebraska, USA), and HONO was measured by long path absorption (LOPAP-03, 
1 QUMA Elektronik \& Analytik GmbH, Wuppertal, Germany). The least sensitive detection

2 limit of the LOPAP was $6 \mathrm{ppt}$, and the resulting minimum detectable flux was $0.004 \mathrm{nmol} \mathrm{m}^{-2}$

$3 \mathrm{~s}^{-1}$. The detection limit for NO was $50 \mathrm{ppt}$, and the minimum detectable flux was $0.04 \mathrm{nmol}$

$4 \mathrm{~m}^{-2} \mathrm{~s}^{-1}$. The uncertainties of the fluxes were calculated using Gaussian error propagation

5 according to Oswald et al. (2013). The gravimetric soil water content during the laboratory

6 soil measurements was calculated from the loss of water using the water vapor measurements

7 in the sample air (see Oswald et al. 2013).

8 Soil properties were analyzed according to standard procedures: $\mathrm{pH}$ was measured according

9 to DIN ISO 10390 in a $0.0125 \mathrm{~mol} \mathrm{l}^{-1} \mathrm{CaCl}_{2}$ solution. Mineral nitrogen (ammonia, nitrite,

10 nitrate) was measured according to DIN ISO/TS $14256-1$ in a $0.0125 \mathrm{~mol} \mathrm{l}^{-1} \mathrm{CaCl}_{2}$ extract

11 with photometric detection of nitrite after reduction of nitrate to nitrite.

Table S1: Soil $\mathrm{pH}$ and nutrient content $\left(\mathrm{NH}_{4}{ }^{+} ; \mathrm{NO}_{2}{ }^{-}\right.$and $\left.\mathrm{NO}_{3}{ }^{-}\right)$for the measured samples in comparison to previously published values (Bargsten et al., 2010 and Gerstberger et al., 2004). * pH values measured by $\mathrm{pH}$ electrode in soil solution (water).

\begin{tabular}{|c|c|c|c|c|}
\hline $\begin{array}{l}\text { Sample } \\
\text { bm = before measurement } \\
\text { am = after measurement }\end{array}$ & $\begin{array}{c}\mathbf{p H} \\
-\end{array}$ & $\begin{array}{c}\mathbf{N H}_{\mathbf{4}}-\mathbf{N} \\
{[\mathrm{mg} / \mathrm{kg}]}\end{array}$ & $\begin{array}{c}\mathbf{N O}_{2}-\mathbf{N} \\
{[\mathrm{mg} / \mathrm{kg}]}\end{array}$ & $\begin{array}{c}\mathbf{N O}_{3}-\mathbf{N} \\
{[\mathrm{mg} / \mathrm{kg}]}\end{array}$ \\
\hline \multicolumn{5}{|l|}{ This study } \\
\hline Sample 1 (bm) & 3.2 & 239.6 & 0.35 & 36.9 \\
\hline Sample 2 (bm) & 3.4 & 49.7 & 0.50 & 5.0 \\
\hline Sample 2 (am) & 3.4 & 6.3 & 0.33 & 2.3 \\
\hline Sample 3 (bm) & 3.1 & 29.2 & 0.89 & 4.9 \\
\hline Sample 3 (am) & 2.9 & 19.4 & 0.13 & 1.7 \\
\hline Sample 4 (bm) & 3.0 & 36.7 & 0.99 & 12.9 \\
\hline Sample 4 (am) & 2.8 & 16.8 & 0.12 & 3.4 \\
\hline Sample 4 (am) replicate & 2.8 & 17.9 & 0.13 & 3.3 \\
\hline Mean (bm) & 3.2 & 38.5 & 0.79 & 7.6 \\
\hline \multicolumn{5}{|l|}{ Bargsten et al. (2010) } \\
\hline M1 (moss) & $4.6^{*}$ & 194 & - & 2 \\
\hline M2 (moss) & $5^{*}$ & 148 & - & 7 \\
\hline G1 (grass) & $4.1^{*}$ & 207 & - & 1 \\
\hline G2 (grass) & $3.6^{*}$ & 204 & - & 2 \\
\hline S1 (spruce) & $3.5^{*}$ & 56 & - & 11 \\
\hline S2 (spruce) & $3.5^{*}$ & 86 & - & 1 \\
\hline B1 (blueberry) & $4.7^{*}$ & 139 & - & 1 \\
\hline B2 (blueberry) & $3.7 *$ & 148 & - & 2 \\
\hline Mean & $4.1^{*}$ & 148 & - & 3.4 \\
\hline \multicolumn{5}{|l|}{ Gerstberger et al. (2004) } \\
\hline $\mathrm{pH}$ in water Oi horizon & $4.5^{*}$ & - & - & - \\
\hline $\mathrm{pH}$ in $\mathrm{CaCl}_{2}$ Oi horizon & 3.6 & - & - & - \\
\hline $\mathrm{pH}$ in water Oe horizon & $3.8^{*}$ & - & - & - \\
\hline $\mathrm{pH}$ in $\mathrm{CaCl}_{2}$ Oe horizon & 2.9 & - & - & - \\
\hline $\mathrm{pH}$ in water Oa horizon & $3.5^{*}$ & - & - & - \\
\hline $\mathrm{pH}$ in water Oa horizon & 2.6 & - & - & - \\
\hline
\end{tabular}




\section{$15 \quad \mathrm{HNO}_{3}$ photolysis}

2

3 We determined the nitrate loading of three spruce trees (Samples 1-19, Table S2) at the

4 clearing site by foliar rinsing, a method previously used to determine $\mathrm{HNO}_{3}$ deposition fluxes.

5 It was shown that nitrate recovery rates are generally better than $90 \%$ for this method (e.g.

6 Marshall and Cadle, 1989; Cadle et al., 1991).

7 Nitrate was washed off the needles using purified water $(18 \mathrm{M} \Omega)$ by exposing a branch length

8 of about $8 \mathrm{~cm}$ to $20 \mathrm{ml}$ purified water in a $40 \mathrm{ml}$ polyethylene flask, and swirling the flask for

$92 \mathrm{~min}$ to assure mixing in the solution and wetting of all parts of the branch. The solution was

10 measured by ion chromatography (Central Analytical Laboratory, University of Bayreuth).

11 The amount of measured nitrate was then normalized to the total needle area, which was

12 determined by harvesting the branch, separating all needles and taking photographs of the

13 needles on a white background containing a scale. These pictures were converted to black and

14 white pictures. By measuring the pixels of the scale, the number of dark pixels (projected

15 needle area) was converted to the needle area (in $\mathrm{cm}^{2}$ ).

16

17 Table S2: Measured leaf nitrate and needle areas of small spruce trees at the clearing site.

\begin{tabular}{lccccc}
\hline Sample & $\begin{array}{c}\text { Time of day } \\
\text { (CET) }\end{array}$ & $\begin{array}{c}\mathrm{NO}_{3}{ }^{-} \\
\mathrm{mg} \mathrm{l}^{-1}\end{array}$ & $\begin{array}{c}\mathrm{NO}_{3}{ }^{-} \\
\text {mol }\end{array}$ & $\begin{array}{c}\text { Projected } \\
\text { needle area } \\
\mathrm{cm}^{3}\end{array}$ & $\begin{array}{c}\text { Geometric } \\
\text { needle area } \\
\mathrm{cm}^{3}\end{array}$ \\
\hline \hline 1 (tree 1) & $16: 00$ & 0.12 & $3.87 \mathrm{E}-08$ & 17.2 & 45.5 \\
2 (tree 1) & $16: 00$ & 0.12 & $3.87 \mathrm{E}-08$ & 12.7 & 33.8 \\
3 (tree 2) & $16: 00$ & 0.09 & $2.90 \mathrm{E}-08$ & 11.7 & 31.0 \\
4 (tree 2) & $16: 00$ & 0.04 & $1.29 \mathrm{E}-08$ & 12.0 & 31.7 \\
5 (tree 3) & $16: 00$ & 0.05 & $1.61 \mathrm{E}-08$ & 21.1 & 56.0 \\
6 (tree 1) & $18: 15$ & 0.06 & $1.94 \mathrm{E}-08$ & 14.7 & 38.8 \\
7 (tree 1) & $18: 15$ & 0.10 & $3.23 \mathrm{E}-08$ & 18.9 & 50.1 \\
8 (tree 2) & $18: 15$ & $<$ & & 16.3 & 43.2 \\
9 (tree 2) & $18: 15$ & 0.09 & $2.90 \mathrm{E}-08$ & 16.9 & 44.8 \\
10 (tree 3) & $18: 15$ & 0.04 & $1.29 \mathrm{E}-08$ & 12.1 & 32.1 \\
11 (tree 1) & 20.15 & 0.10 & $3.23 \mathrm{E}-08$ & 17.8 & 47.3 \\
12 (tree 1) & 20.15 & 0.08 & $2.58 \mathrm{E}-08$ & 23.4 & 62.1 \\
13 (tree 2) & 20.15 & 0.08 & $2.58 \mathrm{E}-08$ & 19.7 & 52.2 \\
14 (tree 2) & 20.15 & 0.06 & $1.94 \mathrm{E}-08$ & 16.0 & 42.5 \\
15 (tree 3) & 20.15 & $<$ & & 12.1 & 32.2 \\
16 (tree 2) & $22: 00$ & 0.09 & $2.90 \mathrm{E}-08$ & 16.0 & 42.5 \\
17 (tree 1) & $22: 00$ & 0.09 & $2.90 \mathrm{E}-08$ & 14.5 & 38.3 \\
18 (tree 3) & $22: 00$ & 0.11 & $3.55 \mathrm{E}-08$ & 19.7 & 52.2 \\
19 (tree 3) & $22: 00$ & 0.13 & $4.19 \mathrm{E}-08$ & 13.8 & 36.5 \\
Mean & & $\mathbf{0 . 0 9}$ & $\mathbf{2 . 8 E - 0 8}$ & $\mathbf{1 6 . 1}$ & $\mathbf{4 2 . 8}$ \\
Standard & & & & & \\
deviation & & $\mathbf{0 . 0 3}$ & $\mathbf{8 . 9 E - 0 9}$ & $\mathbf{3 . 4}$ & $\mathbf{9 . 0}$ \\
\hline
\end{tabular}


1 Additionally, three field blanks have been taken close to the institute building in Bayreuth, 2 where higher $\mathrm{HNO}_{3}$ levels are expected in the gas phase. The blank flasks were kept open to 3 the atmosphere for two minutes instead of being exposed to a branch. The field blanks were 4 below the detection limit of the method (i.e. $\left.<0.03 \mathrm{mg} \mathrm{\textrm {L } ^ { - 1 }} \mathrm{NO}_{3}{ }^{-}\right)$. Nitrite $\left(\mathrm{NO}_{2}{ }^{-}\right)$ 5 concentrations remained below the detection limit in all samples ( $\mathrm{LOD}=0.04 \mathrm{mg} \mathrm{L}^{-1} \mathrm{NO}_{2}^{-}$).

6 The measured nitrate loadings on the trees close to the institute building in Bayreuth (not 7 shown) were 3 to 20 times higher than the maximum values at the Waldstein site.

8 The advantage of the nondestructive method (i.e. not cutting the branches before washing 9 off), which can at least be applied to spruce trees, is that the branches can be marked and 10 sampled several times to establish time series using the same branches. Finally, the branches 11 can be harvested to measure the leaf area index (LAI). The error of the sampling area for the 12 repeated sampling should be low (a few needles more or less). It should be noted that neither the method proposed by Zhou et al. (2011) nor our method discriminates between ammonium nitrate and adsorbed nitric acid, which is supposed to be photolysed to finally yield HONO.

15 Thus the amount of adsorbed $\mathrm{HNO}_{3}$ might be overestimated.

16 The projected needle area can be converted to the total needle area by multiplying by a factor 17 of 2.65 derived by Oren et al. (1986). Thus, if $\mathrm{HNO}_{3}$ is distributed homogeneously on the needle, the amount of $\mathrm{HNO}_{3}$ directly exposed to sunlight is a factor of 2.65 lower. If we then consider only the projected area of the whole branch with needles instead of the single needles, the amount of $\mathrm{HNO}_{3}$ exposed is further reduced by a factor of 2.2 as derived from our branch photographs.

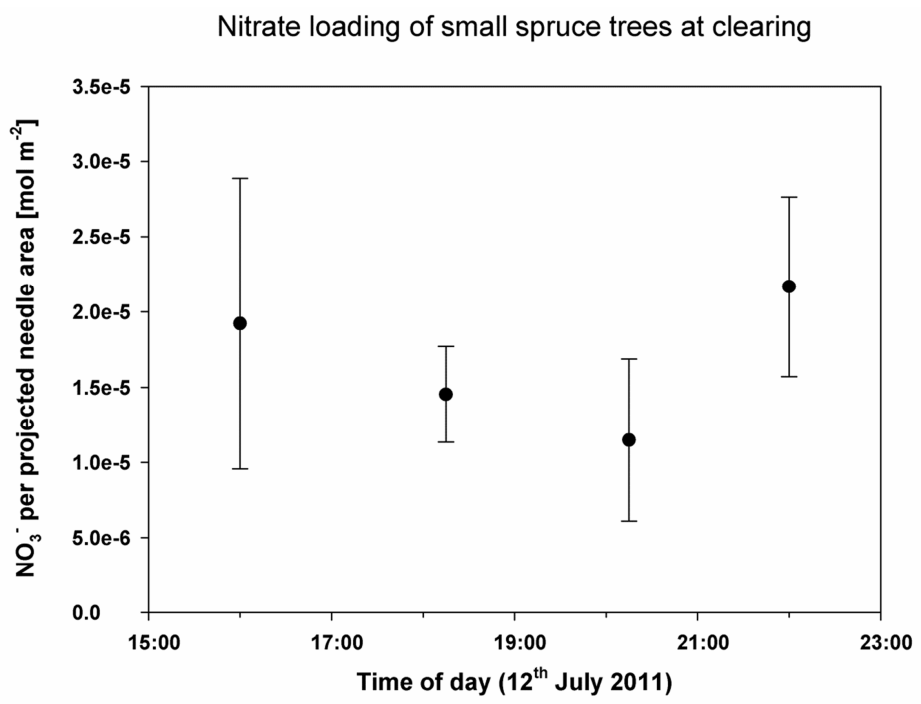


References:

Bargsten, A., Falge, E., Pritsch, K., Huwe, B., and Meixner, F. X.: Laboratory measurements of nitric oxide release from forest soil with a thick organic layer under different understory types, Biogeosciences, 7, 1425-1441, doi:10.5194/bg-7-1425-2010, 2010.

Foken, T., Meixner, F. X., Falge, E., Zetzsch, C., Serafimovich, A., Bargsten, A., Behrendt, T., Biermann, T., Breuninger, C., Dix, S., Gerken, T., Hunner, M., Lehmann-Pape, L., Hens, K., Jocher, G., Kesselmeier, J., Lüers, J., Mayer, J.-C., Moravek, A., Plake, D., Riederer, M., Rütz, F., Scheibe, M., Siebicke, L., Sörgel, M., Staudt, K., Trebs, I., Tsokankunku, A., Welling, M., Wolff, V., and Zhu, Z.: Coupling processes and exchange of energy and reactive and non-reactive trace gases at a forest site - results of the EGER experiment, Atmos. Chem. Phys., 12, 1923-1950, doi:10.5194/acp-121923-2012, 2012.

Gerstberger, P., Foken, T., and Kalbitz, K.: The Lehstenbach and Steinkreuz chatchments in NE Bavaria, Germany, in: Biogeochemistry of forested catchments in a changing environment, a german case study. Ecological Studies, edited by: Matzner, E., Springer, Heidelberg, 15-41, 2004.

Oren, R., Schulze, E.-D., Matyssek, R., and Zimmermann, R.: Estimating photosynthetic rate and annual carbon gain in conifers from specific leaf weight and leaf biomass, Oecologia, 70, 187- 193, 1986.

Serafimovich, A., Eder, F., Hübner, J., Falge, E., Voß, L., Sörgel, M., Held, A., Liu, Q., Eigenmann, R., Huber, K., Ferro Duarte, H., Werle, P., Gast, E., Cieslik, S., Heping, L. and Foken, T.: ExchanGE processes in mountainous Regions (EGER) documentation of the intensive observation period (IOP3) June, $13^{\text {th }}$ to July, $26^{\text {th }}$, 2011, Arbeitsergebnisse Nr. 47, Bayreuth, Germany, print ISSN 1614-8916; internet ISSN 1614-8924, 2011.

Staudt, K. and Foken, T.: Documentation of reference data for the experimental areas of the Bayreuth Centre for Ecology and Environmental Research (BayCEER) at the Waldstein site, Arbeitsergebn., Univ. Bayreuth, Abt. Mikrometeorol., ISSN: 161489166, 35, 35 pp., 2007.

Wu D., Kampf C. K., Pöschl U., Oswald R., Cui J., Ermel M., Hu C., Trebs I., and Sörgel M.: Novel tracer method to measure isotopic labeled gas-phase nitrous acid $\left(\mathrm{HO}^{15} \mathrm{NO}\right)$ in biogeochemical studies, Environmental Science \& Technology, 48, 8021-8027, 2014.

Zhou, X. L., Zhang, N., TerAvest, M., Tang, D., Hou, J., Bertman, S., Alaghmand, M., Shepson, P. B., Carroll, M. A., Griffith, S., Dusanter, S., and Stevens, P. S.: Nitric acid photolysis on forest canopy surface as a source for tropospheric nitrous acid, Nat. Geosci., 4, 440-443, 10.1038/ngeo1164, 2011. 